\title{
LA DISCUSIÓN SOBRE LA ENSEÑANZA DEL DERECHO EN CHILE DENTRO DEL NUEVO PARADIGMA UNIVERSITARIO: UNA TAREA PENDIENTE*
}

\section{JOHANN S. BENFELD ESCOBAR**}

RESUMEN: En este ensayo se afirma que las investigaciones desarrolladas en Chile sobre la enseñanza del derecho no han reparado suficientemente en las cuestiones referidas al cambio de modelo universitario y su influencia en la enseñanza y aprendizaje del derecho. Esto, a su vez, ha impedido a los teóricos nacionales ejercer una mayor influencia en los procesos de reforma al sistema universitario en general y a las modificaciones y proyecciones de la enseńanza del derecho en particular.

PALABRAS CLAVE: Educación superior - paradigmas universitarios enseñanza del derecho - desafíos y riesgos.

\section{THE LEGAL EDUCATION DEBATE IN CHILE UNDER THE NEW UNIVERSITY PARADIGM: A PENDING TASK}

ABSTRACT: This essay argues that research on legal education conducted in Chile has not focused enough on issues related to the change of university model and its influence on law teaching and learning. This, in turn, has prevented national scholars from exercising greater influence on the reform process of the university system in general, not to mention the changes and projections of legal education in particular.

KEYWORDS: Higher education - university paradigm - legal education - challenges and risks.

Un borrador de este trabajo ha sido leído y discutido por los profesores Alan Bronfman, Patricio Lazo y Enzo Solari. A ellos, pues, mi agradecimiento.

Fecha de recepción: 18 de agosto de 2015.

Fecha de aceptación: 8 de septiembre de 2015.

** Profesor de Teoría y Filosofía del Derecho de la Pontificia Universidad Católica de Valparaíso (CHILE). Abogado. Licenciado en Ciencias Jurídicas y Filosofía por la Pontificia Universidad Católica de Valparaíso (CHILE). Doctor en Derecho por la Universidad de Salamanca (España). Correo electrónico: johann.benfeld@cv.cl 
Sumario: 1) Planteamiento del problema. 2) De las universidades de elite a las universidades de acceso masivo. 3) Los autores nacionales frente al problema de la enseñanza del derecho. Una discusión parcial. (3.1.) El Instituto de Docencia e Investigación Jurídicas (1969-1975). (3.2.) 1980 en adelante. Nuevamente el tema a discusión. 4) Consideraciones finales: desafios y riesgos.

\section{1) Planteamiento del Problema}

Prácticamente todas las escuelas de derecho del país han experimentado, en los últimos ańos, una serie de reformas de sus planes de estudio y métodos de enseñanza. Dichas reformas, creemos, han sido motivadas por dos cambios estructurales de diferente naturaleza: la masificación, relativamente rápida, de la enseńanza superior y la aparición de un nuevo modelo económico de gestión de las universidades.

El fenómeno de la masificación de la enseñanza universitaria comenzó a fines de la década de 1960 en los Estados Unidos de Norteamérica y Europa Occidental, como consecuencia natural del desarrollo de las economías capitalistas industrializadas de la posguerra. Muy pronto el aumento de la matrícula universitaria llevó a los teóricos de la educación a plantearse la cuestión de las reformas estructurales de gobierno universitario y de diseńo curricular exigidas por las nuevas circunstancias de la vida universitaria ${ }^{1}$, entre ellas: la diversidad de los nuevos estudiantes, la necesidad de mayores recursos para financiar universidades cada vez más complejas y la importancia de generar puentes de comunicación entre la academia y el mercado laboral. En nuestro país, con todo, este fenómeno no fue perceptible sino hasta la reforma del sistema universitario de 1980, que expandió la oferta universitaria a magnitudes impensadas hasta el momento, junto con implementar un nuevo modelo de gestión económica de las universidades. Sin embargo, como tendremos ocasión de advertir en este pequeńo ensayo, las aproximaciones teóricas que se han realizado en nuestro medio a la cuestión de la enseñanza del derecho no han sido lo suficientemente sensibles a estos cambios estructurales del sistema de educación superior. No lo fueron antes de la década del 80, cuando ya había comenzado el desplazamiento irreversible desde un sistema universitario de elite hacia uno de acceso masivo; y no lo fueron después de la reforma universitaria de 1981, que por razones económicas universalizó la educación terciaria. La falta de comprensión que ha evidenciado la teoría nacional sobre las implicancias del cambio de modelo universitario para

Véase Trow, Martin (1973) Problem in the Transition from Elite to Mass Higher Education. Berkeley: Carnegie Comision on Higher Education, 57 pp. 
la enseñanza del derecho, a su vez, ha impedido que se realicen aportaciones significativas en orden a, por una parte, aprovechar algunas de las oportunidades que el nuevo modelo ofrece (inclusión y movilidad social, aumento del capital humano, vinculación entre la academia y el mundo laboral) y, por otra, a evitar algunos de los riesgos inherentes al mismo (saturación de los mercados laborales, falta de retorno económico por la inversión realizada, tecnificación de la profesión).

\section{2) DE LAS UNIVERSIDADES DE ELITE A LAS UNIVERSIDADES DE ACCESO MASIVO}

Hasta la publicación en 1981 del DFL número 1 del Ministerio de Educación (complementado luego con la Ley Orgánica Constitucional de educación, número 18.962 de 1990), en Chile existían solo 8 universidades. Se trataba de un sistema mixto en que convivían universidades públicas (Universidad de Chile y Universidad Técnica del Estado) con universidades privadas sin fines de lucro (Universidad Católica de Chile, Universidad Católica de Valparaíso, Universidad de Concepción, Universidad Técnica Federico Santa María, Universidad Austral de Chile y Universidad Católica del Norte). Eran pocas universidades como pocos también eran sus alumnos; pues a ellas solo accedían aquellos que hubieran superado las exigentes pruebas de selección. En 1980, a modo de ejemplo, los alumnos matriculados en las universidades chilenas eran poco menos de 120.000. Aunque no todas estas universidades eran necesariamente de excelencia, el sistema en su conjunto era de elite (o, por lo menos, elitista).

El DFL número 1 de 1980 vino a modificar este escenario de una forma dramática. Las 8 universidades tradicionales se transformaron, por vía de división o creación, en 25, y a ellas pronto se sumaron otras 11 nuevas instituciones privadas. Finalmente entre los años 1990 y 2005 se crearon otras 20 universidades $^{2}$, y luego otras cuantas más se sumaron y restaron. De forma tal que al cabo de 30 años las 8 universidades originales se habían convertido en 60 .

De las 60 universidades actualmente existentes en nuestro sistema 41 imparten la carrera de derecho. De ellas, 26 son particulares no tradicionales. Algunas de estas últimas, ofertan la carrera en más de una ciudad (solo a modo ejemplar, la Universidad Santo Tomás imparte la carrera de

\footnotetext{
2 Para un análisis general de la evolución del sistema universitario chileno de este período, véase Cruz-Cocke M. Ricardo (2004) "Evolución de las Universidades Chilenas 19812004". Revista Médica Chilena, 132: 1543-1549 pp., pp. 1544-1545. Un estudio de la evolución de la enseñanza del derecho en nuestro país (sus instituciones y currículos) puede encontrarse en Guzmán B., Alejandro (2006) "La Enseñanza del Derecho. Historia y Perspectivas”. Anales del Instituto de Chile. Santiago: Instituto de Chile, p. 490.
} 
derecho en 9 ciudades diferentes) y otras en varios niveles (pre y postgrado).

Aun cuando el DFL número 1 de 1980 indica con claridad en su artículo 15 que las universidades son entidades sin fines de lucro ${ }^{3}$, cuestión que repite la LOC 18.962 en su artículo 30; en los hechos, muchas de las nuevas instituciones universitarias privadas rápidamente implementaron un sistema de negocio entre empresas relacionadas del ámbito de la construcción, el negocio inmobiliario y la educación. En otras palabras, en solo 30 ańos el sistema de educación universitaria chileno se vio colmado de universidades privadas con fines de lucro, en un porcentaje bastante significativo ${ }^{4}$.

La implementación en Chile de un nuevo modelo de educación terciaria obedeció a múltiples factores. Oscar Espinoza, en un lúcido artículo de 2005, describe el cambio de paradigma nacional como un proceso motivado tanto por elementos exógenos como endógenos. Dentro de los primeros, Espinoza indica la suscripción por parte del Estado de Chile de un conjunto de tratados referidos a materias comerciales (acuerdos de libre comercio y el Acuerdo General sobre el Comercio de Servicios de la $\mathrm{OMC}$ ) directamente vinculados con las directrices del Banco Mundial; el Fondo Monetario Internacional, y el Banco Interamericano de Desarrollo. Los factores endógenos, a su vez, se relacionan con la implementación de un modelo económico neoliberal próximo a la Escuela de Chicago de M. Friedman. La combinación de estos elementos condujo a lo que este autor ha denominado "la privatización y comercialización de la educación chilena”.

Si bien es cierto que el aumento de la oferta universitaria trajo consigo un incremento en las tasas de ingreso a la educación superior chilena (antes de las reformas de 1980 la matrícula en educación superior solo llegaba el $8 \%$ de la población comprendida en el grupo de 18 a 24 ańos de edad), la forma y los motivos tras el aumento de la oferta académica, pronto evidenciaron graves problemas.

3 "Artículo $15^{\circ}$ - Podrán crearse universidades, las que deberán constituirse como personas jurídicas de derecho privado sin fines de lucro".

4 En los Estados Unidos de Norteamérica, sede originaria de este tipo de institución, con el nombre de propietary university se designa un tipo de universidad de baja complejidad y de carácter docente que surgió en la década de los 50 con el único propósito de entregar una formación de corta duración y de naturaleza técnica mercantil (secretariados, administración inicial de empresas o contabilidad básica). Estas universidades se financiaban con la matrícula de sus estudiantes y su funcionamiento y subsistencia dependía (aún hoy) de su eficiencia proveedor de servicios en un mercado regido por las leyes de la oferta y la demanda. Con todo, en el país del norte, estas universidades históricamente han representado un porcentaje ínfimo del sistema de educación superior, y sus compromisos y cometidos siguen siendo, en general, los mismos desde hace 60 años (formar profesionales de nivel medio en un período breve de tiempo). 
"Para nadie es un misterio que este modelo de mercado educativo restringe severamente la autonomía académica y la libertad de cátedra, y orienta el control ideológico y comercial de las universidades hacia un aprendizaje caótico de competencias básicas y laborales, cuyo objetivo es, por una parte, preparar mano de obra barata en los países pobres sin aspiraciones de desarrollo, y por otra, formar profesionales en disciplinas liberales que requieren un bajo costo de inversión para las instituciones de educación superior y que les generan cuantiosas ganancias" 5 .

Esta forma de proceder, también, "ha provocado en Chile, y en otros países de la región, la desaparición de programas académicos con una fuerte orientación social, especialmente aquellos cobijados bajo el alero de facultades de Humanidades y Educación, para sustituirlos por programas que en la teoría son altamente rentables u otros que tradicionalmente lo han sido (por ejemplo, Derecho, Periodismo, Psicología, Ingeniería Comercial), pero en un marco regulatorio absolutamente distinto y con un mercado laboral que aún tenía espacios o nichos para propiciar el desarrollo de los profesionales que se graduaban de esas disciplinas" ${ }^{\text {. }}$

Y, como era de esperar, la tendencia mercantilista de la educación superior chilena lejos de satisfacer las expectativas de los alumnos, sus familias y el propio mercado nacional, produjo "un saturamiento en el nivel formativo en algunas disciplinas como la Ingeniería Comercial, Periodismo, Psicología, Derecho, entre otras. En efecto, anualmente, por ejemplo, se están graduando aproximadamente 2.000 ingenieros comerciales e igual cifra de contadores auditores e ingenieros de especialidad; en un rango un tanto menor aunque no por ello menos preocupante se sitúan los periodistas, los psicólogos y los abogados que se han estado titulando en una cifra cercana a los mil profesionales en cada una de sus disciplinas desde fines de los años noventa"

Así las cosas, la liberalización del mercado de la educación superior en nuestro país, según Espinoza, muy pronto significó un aumento del desempleo ilustrado; un incremento del endeudamiento familiar y una pérdida casi absoluta de control de la calidad de la educación superior (entregada ahora en su mayoría a las nuevas universidades privadas autónomas).

5 Espinoza, Oscar (2005) "Privatización y Comercialización de la Educación Superior en Chile: Una Visión Crítica”. Revista de Educación Superior, Vol. XXXIV, 3, No 135, 41-60 pp., p. 44.

6 EsPINOZA (2005) 44

7 Espinoza (2005) 49. Nueve años después el número de abogados que se tituló el 2014 ascendió a la suma de 3.384, según informó el presidente de la Corte Suprema, señor Sergio Muñoz en su cuenta del año 2015. 
Espinoza, más allá de que uno comparta o no su diagnóstico ${ }^{8}$, indiscutiblemente acierta en denunciar un cambio de paradigma en la educación superior chilena: de una educación de elite pasamos en unas décadas a una educación masificada; los clásicos cometidos universitarios (promoción del conocimiento y búsqueda de la verdad) se adaptaron rápidamente a las exigencias de una economía capitalista y de consumo, y la pronta saturación de los mercados profesionales cambió la manera de comprender el rol del profesional universitario (perfil dinámico y no estático).

Este cambio en el modelo universitario chileno ha sido, en los últimos ańos, expuesto e interpretado por algunos sociólogos de la educación. Así, los trabajo de José Joaquín Brunner referidos a las transformaciones de la universidad en la era global, los cambios de paradigma universitario, los riesgos y desafíos de la educación superior en contextos de mercados económicamente libres y los análisis comparados del modelo universitario chileno con otros paradigmas de educación superior, constituyen, por cierto, verdaderos aportes a la discusión y una buena guía para las futuras políticas públicas sobre el particular ${ }^{9}$. Otro tanto se puede decir de los esfuerzos desplegados el último tiempo por el Centro de Estudios de Políticas y Prácticas en Educación y, especialmente de las contribuciones de Andrés Bernasconi ${ }^{10}$ sobre los nuevos paradigmas universitarios y las transformaciones estructurales y funcionales que los componentes de las universidades (profesores y estudiantes) han experimentado en el último tiempo. Estas contribuciones, como las de otros muchos

8 Aun cuando compartimos con Espinoza algunas de sus críticas y preocupaciones, pensamos que en su análisis faltan algunos elementos. En primer lugar, este autor parece olvidar que el proceso de transformación de las universidades en centros de educación de acceso universal es un fenómeno propio de las sociedades post industriales de naturaleza liberal (que son precisamente las que él parece denostar). Tampoco indica en su artículo, en segundo lugar, que en el modelo norteamericano (paradigma del esquema de negocio que él critica), las propietary univesities constituyen una cifra marginal dentro del sistema; razón por la cual el modelo chileno no puede considerarse tributario de la práctica norteamericana. Tampoco, en tercer lugar, puede atribuirse simplemente a la suscripción de acuerdos internacionales o a la legislación nacional interna sobre el particular el descalabro del sistema de educación universitaria en Chile (piénsese nuevamente en el sistema universitario de los estados Unidos de Norte América). Finalmente, no nos resulta del todo claro, como parece proponer Espinoza, que la única solución a los males de la educación superior chilena pase necesariamente por una intervención radical del estado.

9 Una completa bibliografía de los trabajos de Brunner está disponible en su sitio web: http:// www.brunner.cl.

10 Para revisar las aportaciones del Centro de Estudios de Políticas y Prácticas en educación (como asimismo la bibliografía particular de Bernasconi) véase: http://www.ceppe.cl/home. Con todo, no es el cometido de esta investigación hacerse cargo de las aportaciones generales que los teóricos nacionales de la educación han realizado sobre estos temas. Sin embargo, resulta interesante que, pese a las innegables contribuciones que muchos autores nacionales vienen realizando de un tiempo a esta parte sobre las implicancias del cambio de modelo universitario para el desarrollo y futuro de la academia, sus trabajos continúen siendo en gran medida ignorados por los estudiosos de la enseñanza del derecho. 
profesionales del mundo de la educación, muestran que nuestro país no ha permanecido inmune a los cambios de paradigma que ha experimentado la educación superior en el mundo occidental.

Desgraciadamente, como tendremos oportunidad de ver, en el ámbito particular de la enseñanza del derecho los autores nacionales parecen no tener una clara conciencia sobre el paradigma contemporáneo en el cual desarrollan sus investigaciones y, por lo mismo, en el mejor de los casos, su discusión parece circunscrita a una cuestión de mera didáctica o metodología de la enseñanza del derecho desvinculada de sus supuestos y fines; cuestión que se traduce en la falta de aportaciones concretas que puedan mitigar en parte los problemas que al día de hoy evidencia nuestro sistema.

\section{3) LOS AUTORES NACIONALES FRENTE AL PROBLEMA DE LA ENSEÑANZA DEL DERECHO. UNA DISCUSIÓN PARCIAL}

En la cuestión de la enseñanza del derecho hay involucrados diversos aspectos. Algunos tienen que ver con la forma en que se transmiten los conocimientos y otros con la estructura dentro de los cuales se desarrollan los programas formativos. Así, una cosa es la discusión sobre la didáctica y metodología de la enseñanza del derecho, y otra diferente, pero no separable, es el problema sobre el sistema dentro del cual una y otra se desarrolla.

A nuestro juicio, la cuestión sobre el sistema condiciona de alguna forma la práctica pedagógica y curricular. Por eso, hasta el momento hemos intentado mostrar el cambio de paradigma universitario que ha obrado en nuestro país. Es en este nuevo modelo en el que se desenvuelve el proceso formativo, condicionándolo desde una perspectiva inédita en nuestra historia. Pero, ¿qué añade realmente el trasfondo teórico a la práctica pedagógica y curricular? Nada más y nada menos que el sentido de estas últimas.

En otras palabras, aun cuando los métodos y estrategias por los cuales de manera efectiva la información se transmite de una generación a otra han sido una preocupación constante en la historia del pensamiento occidental ${ }^{11}$, el sentido y propósito que tales métodos y estrategias han tenido ha variado de manera sustancial. De tal forma, si la cuestión a resolver (en términos de didáctica y currículo) hasta antes del cambio de paradigma universitario de los años 60 era cómo enseńar de manera adecuada a ciertas elites para que ellas, dada su condición, pudieran mantener sus

\footnotetext{
11 A este respecto véase a modo ejemplar la monumental Paideia de Werner Jaeger de 1933. Existe edición castellana: Paideia: los Ideales de la Cultura Griega. Traducción Joaquin Xirau y Wenceslao Roces, Fondo de Cultura Económica.
} 
esquemas de privilegios sociales; luego de la transformación de la universidad occidental en un espacio de movilidad social, la cuestión a resolver es cómo a través de la formación universitaria se puede democratizar el conocimiento y suprimir las diferencias de clase, sexo, estirpe y raza. Obviamente, en uno y otro caso ni las estrategias pedagógicas ni los curricula pueden ser los mismos. Y esto es lo fundamental.

Los autores nacionales, hasta donde llega nuestro conocimiento, no han advertido con la intensidad adecuada el cambio de escenario que ha operado en la educación superior. Esto inevitablemente, como veremos a continuación, los ha conducido a discutir casi exclusivamente sobre cuestiones de didáctica, método y currículo jurídico, pero disociados todos de su contexto o, lo que es aún peor, desde un contexto anacrónico: la educación de elite.

Aunque las cuestiones de la enseñanza del derecho en nuestro país tienen cierta tradición ${ }^{12}$, centraremos nuestro análisis en el desarrollo que estas han tenido desde la década del 70 en adelante. La razón de esta estrategia es bastante simple: solo a partir de esta década fue posible que los autores nacionales advirtieran el cambio de modelo universitario, primero como un fenómeno exorbitante a la esfera nacional y luego (una vez introducidas las reformas al sistema chileno de enseñanza superior en 1981) como el contexto en el que las universidades debían adecuar sus prácticas a una nueva realidad. En tal sentido, dividiremos nuestra exposición en dos partes. La primera la dedicaremos a los esfuerzos desplegados por el Instituto de Docencia e Investigación Jurídicas y la segunda a algunos de los trabajos actuales sobre el particular.

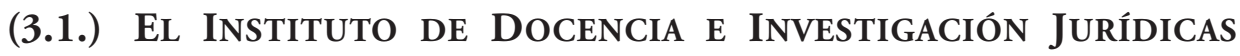 (1969-1975)}

No fue sino hasta 1970 cuando los temas de didáctica y enseñanza del derecho en Chile fueron objeto de una reflexión colectiva y sistemática. En efecto, en julio del referido año apareció el primer número del Boletín del Instituto de Docencia e Investigación Jurídicas.

El propósito del Boletín era, según palabras de Luis Ortiz Quiroga, contribuir en los temas de docencia e investigación jurídicas mediante

12 Véase a este respecto Retamal Ávila, Julio (1973) "Bibliografía Chilena sobre Metodología de la Enseñanza del Derecho". Boletín del Instituto de Docencia e Investigación Jurídicas, No 20, pp. 148-170, p. 148. HüBner Gallo, Jorge (1952) Manual de Introducción a las Ciencias Juridicas y Sociales. Santiago: Editorial Jurídica de Chile, 483 pp. Hübner Gallo, Jorge (1954) Manual de Filosofía del Derecho. Santiago: Editorial Jurídica de Chile, 277 pp. Pacheco Gómez, Máximo (1958) Introducción al Estudio de las Ciencias Jurídicas. Santiago: Editorial Universitaria, 709 pp. 
la "reproducción de artículos, trabajos, conferencias y documentos, tanto nacionales como extranjeros" 13 .

En sus 5 años de existencia el Boletín del Instituto de Docencia e Investigación Jurídicas cumplió sobradamente el cometido que se había propuesto. Una lectura rápida a sus 29 números aparecidos entre julio de 1970 y marzo de 1975 permite comprobar que una gran cantidad de temas de dogmática y teoría del derecho fueron abordados y que prácticamente todos los temas de docencia y enseńanza del derecho fueron también seriamente estudiados.

El primer número del Boletín se inició con un artículo titulado "Salir del Neolítico" de André Tunc ${ }^{14}$. Como su nombre sugiere, la enseñanza del derecho (y el derecho mismo) requerían, según su autor, una renovación profunda para adaptarse y estar a la altura de las circunstancias. Estas nuevas circunstancias eran de variada naturaleza, y los autores que participaron en el Boletín se esforzaron por precisarlas para comprender el nuevo registro en el cual habría de verificarse la investigación y la enseñanza del derecho.

Según Tunc la creciente internacionalización de las relaciones políticas y económicas entre los Estados, en el contexto de una futura apertura de las relaciones entre Occidente y Oriente (en el contexto de la Guerra Fría) exigía volver a pensar en el derecho como una regulación por venir más que como una normatividad históricamente dada. Otros repararon en la conciencia, cada vez mayor, del impacto que el diseño político jurídico tiene en el desarrollo social y en lo mucho que tiene que decir el derecho en tal sentido ${ }^{15}$. Finalmente hubo quien centró su atención en la aparición de nuevas disciplinas de las ciencias sociales que progresivamente comenzaron a colonizar algunos de los territorios propios del saber jurídico poniendo en riesgo el fin y prestigio de la profesión ${ }^{16}$.

Así, de principio a fin, el trasfondo de la discusión efectuada a través del Boletín, en su mayor parte, estuvo marcado por el sentimiento

13 Ortiz Quiroga, Luis (1970) "Introducción al Boletín del Instituto de Docencia e Investigación Jurídicas”. Boletín del Instituto de Docencia e Investigación Jurídicas, No 1, p. 3.

14 Tunc, André (1970) "Salir del Neolítico". Boletín del Instituto de Docencia e Investigación Jurídicas, No 1, pp. 6-22.

15 Tapia Valdés, Jorge (1971) "La Escuela de Derecho y el Cambio Social”. Boletín del Instituto de Docencia e Investigación Jurídicas, No 7, pp. 94-106; Friedman, Lawrence (1972) "Cultura Legal y Desarrollo Social”. Boletín del Instituto de Docencia e Investigación Jurídicas, No 11, pp. 43-61; Seidman, Robert B. (1972) "Derecho y Desarrollo: Un Modelo General”. Boletin del Instituto de Docencia e Investigación Juridicas, No 12, pp. 51-76; Тноме, Joseph R. (1972) "El Derecho Como Instrumento de Cambio Social: Comentarios Sobre un Modelo de Derecho y Desarrollo". Boletín del Instituto de Docencia e Investigación Jurídicas, No 12, pp. 77-94; Lagreze, Feliz (1972) "Ideas para un Programa de Derecho y Desarro1lo”. Boletín del Instituto de Docencia e Investigación Juridicas, No 12, pp. 95-101.

16 Figueroa, Gonzalo (1974) "Hacia Una Nueva Concepción de los Estudios de Derecho". Boletín del Instituto de Docencia e Investigación Juridicas, No 24, pp. 86-125. 
de adecuación a los nuevos tiempos y la forma en que el derecho, dadas las exigencias del momento, debía enseñarse. En este horizonte, primero le tocó el turno a las cuestiones de metodología jurídica; de la cual los artículos de Rafael Valenzuela y Andrés Cúneo fueron señeros en el Instituto ${ }^{17}$. Luego vino el momento de los problemas de modificación curricular; siendo el primer artículo en tal sentido el de Luis Fernando Gómez Duque ${ }^{18}$. El número 11 del Boletín por primera vez reparó en los problemas de pedagogía jurídica de la mano del trabajo titulado "Pedagogía y Derecho" de Hugo Montes ${ }^{19}$. Las cuestiones referidas a evaluación aparecieron por vez primera en el número $12^{20}$.

Desde el número 15 en adelante se observa un cambio editorial del Boletín: cobran mayor importancia los temas de investigación jurídica (artículos especializados) y las cuestiones sobre pedagogía y enseñanza del derecho comienzan a ser variaciones sobre los mismos temas ya tratados. El número 20 del Boletín es, con todo, importante. En él encontramos un interesante artículo de Julio Retamal sobre bibliografía jurídica (que ya hemos citado), que aporta una copiosa literatura sobre el tema de la enseñanza del derecho en Chile hasta 1973 (se trata de 175 artículos científicos sobre estas materias ordenados alfabéticamente). Los números 22, 28 y 29 también son importantes en cuanto en ellos aparecen algunos artículos referidos a la importancia de los cursos de metodología de la investigación ${ }^{21}$ y de diseńo curricular para los primeros programas de magíster en derecho ${ }^{22}$.

Aunque los editores y los miembros del Instituto de Docencia e Investigación Jurídicas conocían de primera fuente los desafíos y problemas que la didáctica jurídica estaba enfrentando en los países del mundo an-

17 Valenzuela, Rafael (1971) "Metodología del Aprendizaje del Derecho". Boletín del Instituto de Docencia e Investigación Jurídicas, No 1, pp. 23-37; Cuneo, Andrés (1971) "Modelo para el Desarrollo de la Metodología Integrada de una Unidad de Materia". Boletín del Instituto de Docencia e Investigación Jurídicas, No 1, pp. 38-70.

18 Gómez Duque, Luis Fernando (1971) "Curriculum y Contenido de la Enseñanza". Boletín del Instituto de Docencia e Investigación Jurídicas, No 8, pp. 98-113.

19 Montes, Hugo (1972) "Pedagogía y Derecho" (versión de cinta magnetofónica). Boletín del Instituto de Docencia e Investigación Jurídicas, № 11, pp. 11-25.

20 Moya, Moisés (1972) "Rol de la Evaluación en Educación". Boletín del Instituto de Docencia e Investigación Jurídicas, No 12, pp. 139-141; Hanitchak, John (1972) "Medición y Evaluación”. Boletín del Instituto de Docencia e Investigación Jurídicas, № 12, pp. 150-159; Green, John A. (1972) "Distintas Formas de Test". Boletín del Instituto de Docencia e Investigación Jurídicas, No 12, pp. 160-164.

21 CAÑAs, Rafael; et al. (1974) "Programa del Curso sobre Investigación Jurídica de la Escuela de Derecho de la Universidad Católica de Chile". Boletín del Instituto de Docencia e Investigación Jurídicas, № 22, pp. 175-184.

22 Bascuñán Valdés, Antonio (1975) "Postgrado en Derecho. Programa de Magíster". Boletín del Instituto de Docencia e Investigación Jurídicas, No 28-29, pp. 41-50. 
glosajón ${ }^{23}$, no fueron del todo permeables a ellos. De hecho, resulta bastante difícil encontrar en los artículos del Boletín una consideración sobre el impacto y presión que ejerce sobre la enseñanza del derecho el nuevo escenario universitario socialmente inclusivo; económicamente preocupado de las tasas de retención y egreso y requerido cada vez más por la práctica profesional. Hay por cierto algunas excepciones.

El trabajo de Jorge Tapia Valdés aparecido en el número 7 del Boletín, de manera explícita advierte el nuevo horizonte en el cual la enseñanza del derecho ha de efectuarse. "Si lo social es consustancial al derecho -escribe Tapia-, todo cuanto concierne al quehacer jurídico estará siempre bajo la influencia de la dinámica social. Referido el problema al tema específico, significará que la forma, orientación y contenido de la enseñanza del derecho dependerán del régimen social, político y económico y, por ende, a cada modificación de ese régimen corresponderá o deberá corresponder una correlativa variación en el régimen de la enseñanza jurídica" 24 .

Luego este mismo autor advierte que "el hecho que, pese a ser claro y evidente, desde hace mucho tiempo, el vigor de la corriente de influencias recíprocas que existe entre derecho, sociedad y enseñanza del derecho, recién en este momento, y en muchos países ni siquiera ahora, comienza a vincularse la reforma de los estudios a la necesidades más amplias y fundamentales que las meras ideas modernizantes o metodológicas que la han inspirado hasta este momento" 25 .

Tapia repara, como pocos, en la necesidad de un nuevo enfoque en la discusión. Ya no se trata simplemente de cuestionar aspectos de didáctica (de la clase expositiva a la participativa), ni de currículo (inclusión o exclusión de cursos en las mallas de las escuelas de derecho), sino de algo más profundo: de precisar el grado de afectación-presión que el contorno social y sus nuevos componentes (los nuevos alumnos de derecho) ha de ejercer de manera cada vez mayor sobre la formación universitaria de los abogados.

Estas ideas se refrendan a la luz del análisis que Tapia realiza sobre lo que él denomina "la condición social del hombre de derecho"26. Cuestión que conduce inevitablemente a enfrentar los temas de docencia y enseńanza del derecho desde la perspectiva de las preguntas sobre "¿quién estudia derecho; por qué y para qué?”27.

\footnotetext{
23 Dentro de los artículos del Boletín es posible encontrar un número significativo de colaboraciones de autores americanos e ingleses.

24 TAPIa VAldÉs, Jorge (1971) "La Escuela de Derecho y el Cambio Social”. Boletín del Instituto de Docencia e Investigación Jurídicas, No 7, pp. 94-106, p. 95.

TAPIA VALDÉs (1971) 97.

TAPIA VAldÉs (1971) 100.

TAPIA VAldÉs (1971) 100.
} 
Desafortunadamente, y por una cuestión de circunstancias, Tapia detiene su análisis en el momento presente de su exposición concluyendo que el hombre de derecho pertenece a una elite nacional social y económica que, por desgracia (de acuerdo a las estadísticas que él mismo entrega), tiende a decrecer progresivamente. El tiempo se encargaría de mostrar cuán equivocado estaba este autor en este diagnóstico.

También en el Boletín es posible encontrar algunos artículos sobre el papel que ha de desempeñar la práctica jurídica en la enseñanza del derecho $^{28}$, que como hemos tenido ocasión de ver era también un tema recurrente en la reflexión sobre la enseñanza del derecho en el mundo anglosajón. Eso sí, los autores nacionales no llegaron en esta época a advertir los riesgos que dichos vínculos podían suponer para las propias cátedras universitarias en el contexto de una economía de libre mercado como la que estaba por instalarse en Chile.

Sin embargo, se trata de consideraciones aisladas dentro de un continente que parece seguir pensando lo jurídico y su enseñanza en el contexto de un sistema universitario de elite. Y, en estricto rigor, no podía ser de otra manera, pues a la sazón solo existían unas pocas escuelas de derecho en Chile; cosa que cambiaría radicalmente a partir de la década de 1980.

Así las cosas, el provincialismo del sistema universitario de aquella época impidió a los teóricos del derecho que se habían ocupado de los temas de docencia y enseñanza del mismo advertir los cambios que estaban próximos a sacudir el sistema universitario nacional (con la multiplicación de las escuelas de derecho a partir de 1980). Es probable que, de haber previsto estos cambios, muchos de los autores que participaron del Boletín habrían podido realizar aportaciones significativas a la reforma del sistema universitario promovida por el régimen militar y, tal vez, el contenido y el alcance de los cambios, por lo menos en lo que a la educación y enseñanza jurídica toca, habría sido diferente.

\section{(3.2.) 1980 EN ADELANTE. NUEVAMENTE EL TEMA A DISCUSIÓN}

Las primeras reflexiones sobre la enseñanza del derecho en Chile, como vemos, simplemente se limitaron a realizar una suerte de relación histórica de las formas y propósitos de la enseñanza jurídica. Por cierto, en ese primer momento Bascunán Valdés fue una excepción, aunque ni siquiera él pudo escapar del todo a sus circunstancias ${ }^{29}$. Los esfuerzos que desplegó luego el Instituto para la Enseñanza y la Investigación Jurídicas,

\footnotetext{
28 Cuneo M., Andrés (1970) "Reforma de las Escuelas de Derecho: el Contenido de la Enseñanza Jurídica”. Boletín del Instituto de Docencia e Investigación Jurídicas, No 3, pp. 32-42.

29 Bascuñán Valdés, Aníbal (1954) Pedagogía Jurídica. Santiago: Editorial Jurídica de Chile, 216 pp., p. 177. Bascuñán Valdés, Aníbal (1961) Manual de Técnica de la Investigación Jurídica. Santiago: Editorial Jurídica de Chile, 217 pp., p. 36.
} 
si bien avanzaron en comparación con sus predecesores, no anticiparon los cambios que estaban por venir, cuestión que hizo que la reflexión llevada a cabo en el Boletín se limitara a materias de didáctica, planificación y currículo vinculadas con las nuevas demandas sociales; pero no con la propia dinámica de los cambios universitarios. Como hemos señalado, la actitud de los teóricos que participaron en el Boletín es del todo comprensible y se encuentra justificada por las circunstancias de su propio y reducido sistema universitario nacional.

Sin embargo, las reformas impulsadas por el régimen militar a partir de la década del 80 alteraron para siempre el sistema universitario nacional. En unos pocos años el número de universidades aumentó de manera significativa, y de la educación de elite, por decreto, se pasó a una de acceso masivo. En este nuevo contexto, era imposible eludir las preguntas que hacía veinte ańos ocupaban buena parte de los pensamientos en el mundo anglosajón y europeo: qué hacer con la diversidad académica; cómo enfrentar el problema de las tasas de retención y egreso, y cómo articular de mejor manera la teoría y la práctica en la enseñanza del derecho considerando el nuevo escenario económico del país.

Por lo anterior, uno esperaría que las aportaciones que los autores nacionales realizaron sobre los temas de enseñanza y didáctica jurídica a partir del 81 no solo se limitaran a las cuestiones que tradicionalmente habían atraído la atención de aquellos que escribieron sobre el particular, sino también se hicieran cargo de los desafíos, oportunidades y amenazas que el nuevo campo de acción a todas luces tenía: aumento de la movilidad social/pérdida de la calidad de la educación; aumento del capital humano y de la utilidad neta social/falta de retorno individual de la inversión personal y familiar; mayor vinculación de la teoría y la práctica/ tecnificación de la enseñanza del derecho y pérdida de la vocación universitaria de la profesión.

Sin embargo, un análisis general de la bibliografía de los últimos años muestra que la teoría no ha logrado alejarse de los temas tradicionales de discusión en materia de enseñanza y aprendizaje del derecho y que, incluso, el registro de la discusión sigue estando muy próximo al de décadas pasadas ${ }^{30}$. Así, en los escritos académicos sobre este tema abundan las consideraciones metodológicas, curriculares, pedagógicas y de evaluación, pero disociadas del contexto presente. También la teoría actual ha sido

30 A modo ejemplar, el volumen 41, no 3 de la Revista Chilena de Derecho (2014) incluye un artículo titulado "Una Propuesta de Clasificación de la Clase Magistral Impartida en la Facultad de Derecho", cuyos autores son F. Elgueta y E. Palma. Aunque los autores introducen en sus análisis un conjunto de consideraciones epistemológicas contemporáneas acompañadas de diagramas explicativos que ilustran a interacción en aula de los diferentes actores de la "clase expositiva"; la verdad es que este era uno de los temas recurrentes de las discusiones sobre metodología de la enseñanza del derecho (casi desde Leibniz en adelante). 
sensible a las exigencias sociales, pero no ha reparado aún en las nuevas exigencias del propio contexto universitario.

Con todo, sería equivocado afirmar que los nuevos trabajos sobre didáctica y enseńanza jurídicas se han limitado a reproducir matizadamente las discusiones pretéritas. Hay por lo menos tres aspectos que le han entregado a la discusión contemporánea sobre estos asuntos una fisonomía propia en nuestro país. En primer lugar, se advierte en la literatura especializada una mayor apertura hacia el trabajo interdisciplinario y, lo que es más significativo aún, la apropiación por parte de los autores nacionales de una nomenclatura técnica de naturaleza pedagógica. En segundo lugar, también se aprecia en la discusión nacional un grado no menor de influencia de la llamada Declaración de Bolonia (1988) y de su consecuencia no prevista: el nuevo Espacio Europeo de Educación Superior. Tanto la declaración original como las sucesivas (v.gr. Declaración de Sorbona 1998), así como las estrategias de adaptación al Espacio Europeo de Educación Superior (plasmados en los comunicados de Praga 2001; Berlín 2003; Bergen 2005, y Londres 2007) han servido de modelo a nuestro propio sistema universitario (de manera totalmente acrítica, por cierto). Finalmente, y muy en línea con todo lo anterior, aun cuando la teoría nacional sigue buscando, a través de la discusión sobre los temas de la enseñanza del derecho, una solución satisfactoria a los nuevos requerimientos sociales para la profesión de abogado, la transformación cultural experimentada en nuestro país en los últimos 30 años ha hecho que la reflexión sobre tales requerimientos se vea considerablemente disminuida, limitándose a una teorización casi exclusiva de los aspectos económicos del contexto social. En otros términos, la idea de una educación jurídica acorde a las "exigencias sociales" ha dado paso a una enseńanza del derecho congenial con las "necesidad del mercado".

Puesto que, entre otros, son estos tres aspectos señalados los que han dado una nueva cara a la reflexión nacional sobre la enseñanza del derecho, no resulta difícil encontrar en la actual literatura especializada continuas referencias hacia ellos.

A nivel institucional, el contenido de las actas de los 4 congresos nacionales que se han realizado sobre los temas de pedagogía universitaria y didáctica jurídica, desde el año 2010 hasta la fecha, a instancias de la Unidad de Pedagogía Universitaria y Didáctica Jurídica de la Facultad de Derecho de la Universidad de Chile ${ }^{31}$, muestra que las cuestiones relacionadas con los aspectos de enseñanza del derecho i.- se abordan desde

31 Esta Unidad puede ser vista, en su intención, como una continuación de la labor del Instituto de Docencia e Investigación Jurídicas que dejó de funcionar en 1975. En esta dirección, los trabajos que se han presentado en los diferentes congresos tienen un marco de discusión institucional e incluso una cierta línea editorial (sobre qué va a tratar el respectivo congreso). 
una perspectiva más general (la de la pedagogía universitaria) que supone la necesidad de un diálogo previo con otras disciplinas, especialmente con las ciencias pedagógicas y la psicología; ii.- se someten a criterios objetivos de optimización de resultados (sistemas de aseguramiento de la calidad de la educación), y iii.- se discuten desde una nomenclatura especializada congenial con el programa de Bolonia (destrezas cognitivas; habilidades y competencias). Desgraciadamente las actas no proporcionan en todos los casos un buen material científico, pues una gran cantidad de ellas tienen por contenido únicamente presentaciones breves que buscan más bien propiciar una discusión que mostrar el resultado de una investigación rigurosa sobre el tema. Aunque, por cierto, hay excepciones ${ }^{32}$.

En el ámbito individual, las publicaciones especializadas (que no han sido muchas) siguen la misma tendencia que las presentaciones y ponencias de las Actas de los congresos de pedagogía universitaria y didáctica jurídica al momento abordar los temas tradicionales sobre enseńanza del derecho: currículos, métodos y evaluación.

Así, por ejemplo, hace algunos años, Alejandro Guzmán mostró mediante un minucioso estudio histórico que la enseñanza del derecho en Chile ha adolecido de una falta grave: ha sido incapaz de adecuarse a los cambios, manteniéndose de forma casi irracional atrapada en una tradición curricular que progresivamente ha hecho cada vez más irrelevante la figura del abogado como arquitecto social. ${ }^{33} \mathrm{La}$ rigidez que ha mostrado el diseño curricular de la enseñanza del derecho en Chile no ha pasado desapercibida para los autores. Recientemente Enzo Solari en un artículo titulado "El Currículo Chileno de Estudios Jurídicos", mediante un interesante estudio comparado entre los regímenes curriculares del sistema chileno, norteamericano, alemán y español, ha puesto de manifiesto la urgente necesidad de reforma del currículo de las escuelas de derecho na-

32 Las presentaciones y ponencias de estos congresos, con excepción del tercero, se encuentra disponible en la siguiente dirección: http://www.xn--enseanzadelderecho-q0b.cl/index.php/ publicaciones

33 De manera muy lúcida Guzmán sintetiza sus ideas en el siguiente párrafo: "el período entre 1973 y 1990 puso término en Chile a los últimos y ya debilitados vestigios de la vieja cultura de abogados del siglo XIX, que había diseñado el Estado y su aparato administrativo, empezado y consumado la codificación, creado y desarrollado la universidad y, más en general, el sistema educacional del país, dirigido su economía y sus finanzas, y, en fin, gobernado a Chile desde la presidencia de la república, los ministerios, el Congreso Nacional y, por supuesto, los tribunales de justicia. Los dos intentos que hubo por modernizar el perfil clásico del abogado en el siglo xx, merced a la absorción de ciencias extrańas a su ethos espiritual, como la Economía primero, y las Ciencias sociales después, como para conservarle desesperadamente su papel rector en la sociedad, hubieron de fracasar”. GuZMán B. (2006) 343. Para un estudio detallado de la evolución de la cultura jurídica nacional véase también Peña, Carlos; et al. (1994) Evolución de la Cultura Jurídica Chilena. Santiago de Chile: Corporación de Promoción Universitaria. 
cionales, en consideración a las necesidades contemporáneas y a la experiencia internacional (que a nivel universitario funciona de modelo).

Las críticas de Solari parecen apuntar en dos direcciones diversas, pero complementarias. Por una parte, está la cuestión de la extensión y contenido del currículo nacional, y, por otra, la preocupante tecnificación de la profesión cada vez más falta de un sustrato cultural humanista que le permita contrarrestar de forma crítica las tendencias de un mercado universitario y laboral cada vez menos consciente de su vocación.

Con respecto a lo primero, esto es, la extensión y contenido del currículo jurídico chileno, Solari, luego de haber repasado los sistemas alemán, norteamericano y español señala: "pues bien, a la luz de lo anterior hay que volver a las cuestiones con las que comenzaba este texto. Estas pueden encararse ahora con mayor conocimiento de causa y sin rodeos: ¿habrá una buena razón para que lo que toma tres o cuatro años en muy buenas universidades extranjeras tenga que tomar cinco años en las chilenas? Todo indicaría, en efecto, que la licenciatura, que entre nosotros demora no menos de cinco años $-y$ respecto de la cual quizá aún se crea que constituye la única formación jurídica que recibirá el abogado chileno- se desdobla en otros lugares entre un pregrado bastante más breve y unos necesarios posgrados ulteriores. ¿No habría que pretender por ende para la carrera de Derecho una menor duración y un mayor énfasis en la formación humanística e incluso científica, sea esta contemporánea de estudios jurídicos entendidos como pregrado, sea anterior a aquellos si es que fueran entendidos como posgrado? ¿Hay ya algún síntoma alentador al respecto en el panorama chileno?" 34 .

En cuanto a la necesidad de una base humanista mayor, Solari declara, una vez que ha repasado el papel que han jugado las humanidades en las tradiciones jurídicas de Alemania, Estados Unidos de América y España como promotoras de una verdadera "cultura jurídica", que "semejante papel cultural de los estudios universitarios, aun de los más tecnificados e instrumentales, y sin el cual estos terminan facturando profesionales sumamente ignorantes y poco universales, es lo que impulsa algunas recientes y cerradas defensas de la educación humanística. Luego del famoso alegato de A. Bloom - The Closing of the American Mind-, ha elevado últimamente la voz M. Nussbaum bajo la forma de una franca requisitoria de la educación superior "con fines de lucro, la que, a su modo de ver, es peligrosa para la democracia y sus ciudadano" 35 .

Ahora bien, aun cuando la historia muestra que no ha habido en nuestro país grandes innovaciones curriculares en la enseñanza del dere-

\footnotetext{
34 Solari, Enzo (2012) “El Currículo Chileno de Estudios Jurídicos”. Revista de Derecho, Vol. XXXIX, No 2, pp. 703-734, p. 721.

35 Solari (2012) 719.
} 
cho, de ello no se sigue que la forma en que dichos currículos se enseñan no haya sido más permeable a la influencia externa. En efecto, en materia de metodología y didáctica jurídica, los autores nacionales contemporáneos han introducido un conjunto de consideraciones del extrarradio jurídico (ya de la terminología propia de las ciencias de la educación ya de la imitación de procesos internacionales como el de Bolonia), cuestión que ha elevado el nivel de la discusión, por lo menos conceptualmente.

En la dirección anterior avanzan, por ejemplo, las aportaciones de Lazo y Coloma. Bajo el título "Formación Jurídica, Competencias y Métodos de Enseńanza: Premisas"; Patricio Lazo trata de manera sistemática los conceptos de "competencia"; "modalidad", "métodos de enseñanza" y "evaluación" desde la perspectiva de la enseñanza del derecho. En su trabajo dichos conceptos se delinean teóricamente mostrando su concatenación dentro del proceso de la enseñanza-aprendizaje del derecho. De forma tal que partiendo de la noción de competencia, entendida como un conjunto de destrezas, habilidades y capacidad resolutiva de problemas de índole moral, se inquiere sobre la mejor manera de realizarla en la práctica. Esta cuestión a su vez nos conduce al tema de las modalidades y métodos, que Lazo se apresura a distinguir, toda vez que "la identificación de las competencias lleva, como es lógico, a la reflexión acerca del cómo se han de desarrollar aquéllas, lo que nos coloca frente al problema de la modalidad y del método de enseńanza. El concepto de modalidad de enseñanza es más amplio que el de método, puesto que remite a la forma de organización de los procesos de enseñanza-aprendizaje, cuyos ejes son los propósitos del docente y los recursos de la institución universitaria. Las modalidades proporcionan un marco muy amplio de actuación, dentro del cual pueden desenvolverse los métodos" 36 .

La discusión que Lazo realiza sobre estas materias tiene como trasfondo la identificación de un problema: la falta de competencias básicas que los operadores jurídicos actualmente detectan en el medio laboral. De ahí que su artículo se inicie con una reflexión sobre las palabras del entonces presidente de la Corte Suprema, señor Urbano Marín y, a propósito de ellas, de la forma de revertir esta situación. La solución, cree Lazo, de momento no reside en la implementación de un examen nacional de habilitación (que es lo que la Corte Suprema cada cierto tiempo propone ${ }^{37}$ ), dada la falta casi total de criterios para la realización de tal examen.

36 Lazo, Patricio (2011) "Formación Jurídica, Competencias y Métodos de Enseñanza: Premisas”. Revista Ius et Praxis, Año 17, No 1, pp. 249-262, p. 256.

37 Este año no ha sido la excepción. En la cuenta anual del Presidente del Supremo tribunal del país, página 30, don Sergio Muñoz ha vuelto a instalar el tema, luego de informar sobre el número exorbitante de nuevos abogados graduados el año 2014 (3.384). Discurso disponible en: http://www.pjud.cl/documents/10179/1478806/Discurso+con+motivo+de+la+cu enta + p $\%$ C3\%BAblica+e+inicio $+d e l+a \% C 3 \% B 1 o+j u d i c i a l+2015$.pdf $/ 8281 b f d f-01 e 1-494 f-$ ad02-c7f5ef862515? version $=1.1$. 
Por el contrario, la implementación gradual y consciente de las modernas técnicas pedagógicas, recogidas en la declaración de Bolonia y en el Informe Tuning para Latinoamérica, avanzan, según su parecer, en la dirección correcta para el desarrollo de competencias jurídicas específicas en el marco de unas modalidades bien definidas y unos método idóneos.

Rodrigo Coloma, quien también ha mostrado interés por estos temas, ha publicado hasta el momento tres interesantes artículos cuyos títulos son: "El ocaso del profesor Binns. Un ensayo acerca de la enseńanza del derecho en Chile" de 2005, "Hacia una enseñanza del Derecho Efectiva" de 2006 y "Los Abogados y las Palabras. Una propuesta para Fortalecer Competencias Iniciales en los Estudiantes de Derecho" de 2012.

En el segundo de estos trabajos, al igual que Lazo, Coloma reflexiona sobre el concepto de competencia, entendido como "la capacidad para realizar algo que no habría podido hacerse, de no haber mediado el proceso de enseñanza (es por esa razón de que se ha hablado de competencias adquiribles en el denominador y de competencias adquiridas en el numerador)"38; para luego de manera lúcida mostrar de qué manera existe una desarmonía entre las competencias esperadas para la práctica profesional de los abogados y las deseadas para los estudiantes de derecho. Al respecto escribe: "Lo que explica en gran medida el aletargamiento en la implementación de algunos cambios que parecen bastante obvios (en la enseñanza del derecho), es la existencia de un abismo que separa, por una parte, las ideas que probablemente podríamos llegar a compartir (al menos parcialmente) acerca de las propiedades que serían constitutivas de un buen abogado y, por la otra, las creencias relativas a quienes serían buenos estudiantes de derecho. Habría así un espacio separando ambas categorías que quedaría en tierra de nadie y que explicaría a lo menos parcialmente el éxito profesional inesperado de alumnos tildados de mediocres o el fracaso, también inesperado, de estudiantes brillantes"39. A esta conclusión se arriba, según este autor, mediante un examen de los métodos tradicionales de enseñanza del derecho en Chile, caracterizados por su propensión al desarrollo de la memoria y a una actitud cómodamente pasiva del sujeto cognoscente.

A lo anterior Coloma ańade la falta casi absoluta de criterios objetivos que permitan medir la efectividad de los tiempos y logros del proceso de aprendizaje del derecho en los diferentes programas que se ofertan en el país. En otras palabras, en Chile la enseñanza del derecho no es efectiva.

\footnotetext{
38 Coloma, Rodrigo (2006) "Hacia una enseñanza del Derecho Efectiva”. Revista Escuela de Derecho, Año 7, N 7, pp. 123-141, p. 129.

39 Coloma (2006) 134.
} 
En "el Ocaso de Profesor Binns", Rodrigo Coloma advierte, a su vez, que el tipo de método de enseñanza del derecho utilizado tradicionalmente en Chile (la clase expositiva) es en buena medida el responsable de los magros resultados obtenidos en la adquisición de las competencias esperadas en los futuros abogados. Este método se caracteriza por considerar a los estudiantes como "acumuladores del conocimiento vertido por sus profesores mediante la exposición didáctica (o de la lectura de textos). El énfasis de los aprendizajes estaría puesto en la adquisición de contenidos conceptuales. Su característica principal es que se presenta como ofreciendo una especificación clara de qué hay que aprender exactamente; y otra característica es que sugiere criterios para evaluar sus logros. Para dar cuenta de este modelo se podría pensar en los estudiantes como recipientes a ser llenados. El proceso de enseñanza aprendizaje será exitoso en la medida que el aprendiz incorpore a su memoria -y sea capaz de recuperar fielmente- lo ya expresado por el maestro en el aula o lo que ha sido escrito en los libros de texto. En su forma más pura, y en lo que respecta a los conceptos, se esperaría que el estudiante desempeñe un papel semejante al de un juglar conservando en forma prístina lo aceptado por la ciencia normal o, lisa y llanamente, por el profesor" 40 .

Esta forma de concebir a los estudiantes de derecho, obviamente, no se condice con lo que es deseable en un abogado (un mediador competente de los conflictos sociales). De este último se espera una capacidad resolutiva de conflictos, poder de análisis y síntesis, imaginación e innovación en las soluciones, etc. Ahora bien, la falta de simetría entre la formación jurídica universitaria y la expectativa social de la profesión de abogado se materializa en la proliferación de "abogados plomeros". "El abogado plomero es visto 'esencialmente como alguien que es maestro en cierto conocimiento especializado, 'el derecho', y en ciertas destrezas técnicas'. Sin perjuicio de que el mercado requiere de abogados plomeros que puedan abocarse eficientemente a sugerir o defender soluciones estandarizadas para hacer frente a ciertos problemas, un sistema de formación que solo produzca esta clase de abogados resulta extremadamente conservador del statu quo" 41 .

Según Coloma son varios los factores que inciden en el statu quo (tanto de la enseñanza del derecho como de sus instituciones). Entre ellos, "sin lugar a dudas la tríada currículo rígido y centrado en objetivos conceptuales extensos pero de baja profundidad-clase magistral- evaluación del recuerdo, posibilitan la proliferación de carreras de derecho de bajo presupuesto. La coexistencia de tales elementos favorece la realización de

40 Coloma, Rodrigo (2005) "El ocaso del profesor Binns. Un ensayo acerca de la enseñanza
del derecho en Chile". Revista Ius et Praxis, Año 11, No 1, pp. 133-172, p. 147.

41 Coloma (2005) 151. 
clases masivas con una baja demanda de materiales de apoyo a los aprendizajes y que no requieren gran preparación por parte de los profesores, una vez que ellos han organizado un discurso de base. El único gasto adicional de importancia que tendría que incurrirse correspondería a la habilitación de una biblioteca relativamente bien surtida" 42 .

Finalmente, en "Los Abogados y las Palabras. Una propuesta para Fortalecer Competencias Iniciales en los Estudiantes de Derecho", Coloma y Agüero se hacen cargo de las competencias deseables para el aprendizaje significativo de los estudiantes de derecho. Estas competencias son identificadas en el texto como las de comprensión de textos y discursos con contenido jurídico y producción de documentos y textos de igual naturaleza.

Los trabajos de Coloma, en todo caso, no solo son interesantes desde el punto de vista de la modalidad, método, didáctica y evaluación de la enseñanza del derecho, sino también son importantes porque en ellos el autor ha reparado en dos cuestiones relacionadas con el cambio de paradigma universitario: i) la desarmonía que existe entre los perfiles actuales de egreso de un estudiante de derecho (vinculados a las exigencias de un mercado laboral agresivo y dinámico) y la forma en que de facto se concibe al alumno de derecho (cuestión que condiciona la modalidad, el método, la didáctica y la evaluación). Y ii) en los tres textos citados, con mayor intensidad que otros autores nacionales, Coloma ha señalado en necesidad de tomar en consideración el nuevo tipo de alumnos que ingresa al sistema universitario en general y a las escuelas de derecho en particular. A este respecto escribe: "como recurrentemente se llama la atención en conversaciones y en textos especializados, en Chile, en los últimos treinta ańos, ha aumentado de forma explosiva el número de estudiantes de derecho y junto a ello se ha producido una diversificación del mercado universitario. Esta transformación fue impulsada por medidas políticas y económicas las cuales han incidido en que en el día de hoy encontremos, por un lado, muchos estudiantes provenientes de múltiples contextos socioeconómicos y culturales, y, por el otro, un sistema universitario que no ha sido diseñado para asumir el desafío de producir aprendizajes en grupos humanos altamente heterogéneos. En otras palabras, las prácticas pedagógicas dominantes en las universidades no se hacen cargo de la circunstancia de que los estudiantes que ingresan a sus aulas posean competencias y conocimientos previos muy diversos entre sín 43 .

Las reflexiones, comentarios y críticas que realizan Lazo y Coloma, por cierto, tienen un sustrato común: todas ellas están movidas por las nuevas tendencias de las ciencias pedagógicas que han sido recogidas en

Coloma (2005) 158.

Coloma, Rodrigo y Agüero, Claudio (2012) "Los Abogados y las Palabras. Una propuesta para Fortalecer Competencias Iniciales en los Estudiantes de Derecho". Revista de Derecho Universidad Católica del Norte, Año 19, No 1, pp. 39-69, p. 43. 
el espacio europeo de educación superior, especialmente por el proceso de Bolonia, y en nuestro contexto próximo, y por influencia del mencionado proceso, en el documento titulado "Criterios para la Evaluación de la Carrera de Derecho” de la Comisión Nacional de Acreditación ${ }^{44}$. En todo caso, aun cuando resulta evidente el marco conceptual en el que actualmente se mueve la enseñanza del derecho en Chile, al parecer ningún autor se ha hecho cargo de precisar el sentido y alcance que las directrices de proceso de Bolonia han de tener en nuestro sistema ${ }^{45}$.

Además de las precedentes aportaciones, los autores nacionales también han indagado en aspectos particulares de la enseñanza del derecho en Chile. Algunos han escrito sobre la enseñanza del derecho circunscrita a los cursos de dogmática jurídica especializada ${ }^{46}$; otros, en cambio, han ampliado el horizonte de la discusión reflexionando sobre la importancia del estudio de las humanidades en la formación de los abogados ${ }^{47}$; tam-

44 Disponibles en: https://www.cnachile.cl/Criterios\%20de\%20carreras/derecho.pdf

45 Ha faltado una reflexión al modo de la realizada por Manuel J. Peláez a propósito de la implementación del programa de Bolonia en las facultades de derecho italianas (Peláez, Manuel (2004) "Las Asignaturas Jurídicas en las Licenciaturas de Especialidad en Italia en el Marco de la Reforma Europea de la Educación Universitaria". Revista de Derecho Pontificia Universidad Católica de Valparaíso, XXV, pp. 331-338).

46 A este respecto resultan significativos los siguientes trabajos: Campusano, Raúl (2002) "La Enseñanza del Derecho Informático en Chile. Apuntes para una Respuesta". Actualidad Jurídica, No 5; CATTÁN, Ángela (2002) "Algunas notas para una Nueva Metodología para la Enseñanza del Derecho Romano". Actualidad Jurídica, No 5; AlveAr, Julio (2002) "Algunas Anotaciones sobre la Enseñanza de la Ética Jurídica". Actualidad Jurídica, № 6, pp. 27; Agudelo, Martín (2000) "Hacia un Procesamiento Adecuado de la Justicia: una Propuesta de Enseñanza del Derecho Procesal para la Sociedad del Nuevo Milenio". Revista de Derecho Universidad Central, No 1. Salas, Julio (1991) "La Enseñanza del Proceso". Revista de Derecho Universidad de Concepción, No 189. Veloso, Adolfo (1998) "Acerca del Derecho Internacional y su Enseñanza". Revista de Derecho Universidad de Concepción, No 207. Carvallo, Sergio (1986) "La Cátedra de Derecho Económico". Temas de Derecho, No 1, p. 34. HervadA, Francisco (1989) "La Enseñanza del Derecho Natural y del Derecho Canónico en las Facultades de Derecho". Revista Chilena de Derecho, Vol. 16, No 3, p. 565. Pedrals, Antonio (1984) "La Enseñanza, de la Teoría General del Derecho". Anuario de Filosofía Jurídica y Social, Sociedad Chilena de Filosofía Jurídica Social, No 2. Palomino, José F. (1998) "David Sobrevilla y la enseñanza de la Filosofía del Derecho en la Universidad de Lima”. Anuario de Filosofía Jurídica y Social, № 16; EsCandón, Jesús (2006) "Inquietudes persistentes respecto a la enseñanza de la Filosofía del Derecho". Sociedad Chilena de Filosofía Jurídica Social Anuario de Filosofía Jurídica y Social, No 24; Amunátegui, Carlos (2007) "La enseñanza del Derecho Romano a través de Gayo. Una experiencia docente". Ius Publicum, $\mathrm{N}^{\circ} 18$. Calvinho, Gustavo (2009) "La enseñanza del derecho procesal en el siglo XXI". Revista de Derecho Universidad Católica de la Santísima Concepción, 2, No 20.

47 En este sentido avanzan los trabajos de Cárcamo, Juan (2000) "La Orientación Humanista en el estudiante de Derecho". Revista de Derecho Universidad Central, No 1; Cárcamo, Juan (2002) "Cooperación a la Justicia como Aspecto Formativo Fundamental del Estudiante de Derecho". Revista de Derecho Universidad Central, No 3; Pezzeta, Silvina (2008) "La enseñanza del Derecho desde una perspectiva sociológico jurídica. Un estudio de caso en una Facultad de Derecho". Revista de Derecho Universidad Católica del Norte, Vol. 15. No 2; VALenzuela, Rodrigo (2002) "El derecho y las humanidades". Revista de Derecho Universidad Austral de Chile, Vol. XIII. 
bién se ha reparado en la profesión de abogado como criterio modelador de la enseñanza del derecho ${ }^{48}$. El profesor de derecho ha sido, en algún trabajo, objeto de estudio por parte de la doctrina ya en su dimensión personal ${ }^{49}$ ya en su responsabilidad en la elección de los métodos adecuados para la enseńanza del derecho ${ }^{50}$. Finalmente, también es posible encontrar algunos trabajos que tratan el tema de la enseñanza y el aprendizaje del derecho en términos generales ${ }^{51}$.

Como se aprecia, los autores nacionales no han descuidado en los últimos años el tema de la enseñanza del derecho. La producción actual, con todo, dista mucho de equipararse, por lo menos en volumen, al período en que funcionó el Instituto de Docencia e Investigación Jurídicas. Aunque, a su vez, las circunstancias del momento presente han entregado un nuevo escenario para la educación superior y nuevas herramientas conceptuales para abordar los temas tradicionalmente vinculados a ella, cuestión que ha conducido a una reflexión más técnica e interdisciplinaria de la que se había realizado en la década del setenta.

Ahora bien, desgraciadamente, con excepción de las aportaciones de Coloma, los autores nacionales que han estudiado y escrito sobre la enseñanza del derecho, sin perjuicio de haber realizado notables aportaciones y avances en la discusión sobre los temas clásicos sobre enseñanza y aprendizaje, han dicho muy poco la forma que el nuevo paradigma de universitario (masivo y comprometido con el mercado) influye en la enseñanza del derecho. Desgraciadamente esta falta se ha traducido en una escasa aportación en la discusión sobre la reforma de los planes de estudio de la carrera de derecho, muchos de los cuales se han realizado de manera

48 Aróstica, Iván (2009) "Formando Abogados Analistas". Actualidad Jurídica, No 19, Tomo II; Manning, Bayless (1989) "Atributos del Abogado". Temas de Derecho, No 1; Shakhtur, Ali (2007/2008) "El Rol del Abogado: ¿Negociador?”. Temas de Derecho, No 1 y 2; AbramovicH, Víctor (1999) "La enseńanza del derecho en las Clínicas Legales de Interés Público". Cuadernos de Análisis Juridico Universidad Diego Portales, Serie Publicaciones Especiales, No 9.

49 Devoto, Carolina (2014) "Hacia una Caracterización teórica del Docente Universitario en la Carrera de Derecho". Actualidad Jurídica, No 30; Squella, Agustín (1995) “¿Qué he Aprendido Enseñando Filosofía del Derecho?”. Gaceta Jurídica, No 178; Jiménez, Manuel (2011) "La movilidad académica como factor auxiliar del aprendizaje del Derecho". Revista de Derecho, Universidad Católica de la Santísima Concepción, No 24, Vol. 2.

50 Devoto, Carolina (2012) "El Método de Resolución de Casos en la Enseñanza del Derecho". Actualidad Jurídica, No 25; TAELI, Raquel; et al. (2014) "Los aportes de paradigmas complejos y constructivistas para la enseñanza de la ciencia jurídica”. Ius et Praxis, No 1; Caprile, Bruno (2000) “La Enseñanza del Derecho: ¿Clase Magistral o Método activo?”. Actualidad Jurídica, No 2.

51 Otárola, Waldo (2000) "La Enseñanza del Derecho". Revista de Derecho Universidad de Concepción, No 207; Guerrero, Roberto (1997) "La Enseñanza del Derecho en Chile: una Visión Crítica”. Revista Chilena de Derecho, Vol. 24, No 1; Donoso, Andrés (2001) "La Educación Jurídica: ¿Un Problema Insoluble?”. Revista de Derecho Universidad Finis Terrae, Año V, No 5. 
acrítica y de forma meramente congenial con las exigencias del mercado económico.

\section{4) CONSIDERACIONES FINALES: OPORTUNIDADES, DESAFÍOS Y RIESGOS PARA LA ENSEŃANZA DEL DERECHO DENTRO DEL NUEVO PARADIGMA UNIVERSITARIO}

No es el propósito de este ensayo suplir la deficiencia que él denuncia, es decir, la falta de vinculación de los temas de la enseñanza del derecho a las cuestiones asociadas al cambio de paradigma universitario: diversidad estudiantil y de claustro; tasas de retención y egreso - retorno de capital humano e incremento de utilidad social neta; y relaciones entre la teoría y la práctica. Para realizar un cometido así probablemente habría que iniciar una empresa colectiva, multidisciplinaria, que incluyera análisis conceptuales y empíricos a fin de proponer, con algún grado de fiabilidad, reformas sustanciales al modelo universitario chileno en general y a la enseñanza del derecho en particular.

Sin embargo, a modo de conclusión podemos conjeturar algunas oportunidades, desafíos y riesgos evidentes que el nuevo paradigma universitario entrańa para la enseñanza del derecho.

Las oportunidades que presenta el nuevo modelo universitario son de variada índole. La diversidad en las aulas y los claustros puede llevar a una democratización profunda en la adquisición e intercambio del conocimiento. Junto a ello, la diversidad, entendida como un valor, puede constituir un nuevo referente para la integración social (y no solo la movilidad de clase) que, desde un horizonte diverso, entregue las respuestas que la sociedad del siglo XXI requiere. Estos elementos referidos en particular a la enseñanza del derecho pueden servir, a su vez, como criterios necesarios en la formación de todo abogado que pretenda contribuir de manera decisiva al desarrollo de su comunidad, recuperando para sí su condición de arquitecto social. Los esfuerzos encaminados a optimizar las tasas de ingreso, retención, egreso y titulación de universitarios, en un número muy superior al de décadas pasadas, puede conducir al aumento de capital humano e incremento social neto de utilidades en el mediano plazo, cuestión que tiene la aptitud de redundar en un mejoramiento progresivo y constante de las condiciones de vida no solo para quien accede a la educación superior sino para la sociedad en su conjunto, entendiendo que esta es una empresa colectiva para el beneficio recíproco de sus miembro. La vinculación competencial entre los estudios universitarios del derecho y los desafíos del mercado laboral y las exigencias propias de la sociedad se puede traducir en una mayor eficacia, eficiencia y productividad del esfuerzo individual en el trabajo colectivo. Sin embargo, para que todas estas oportunidades se transformen en realidad es menester que el sistema 
universitario en su conjunto, y la enseñanza del derecho en particular, asuma con seriedad los desafíos inherentes a las oportunidades.

Un sistema universitario de acceso universal, caracterizado por la diversidad y aumento del número de sus matrículas, necesariamente debe resolver el problema que supone, por una parte, el aseguramiento de la calidad de la educación con el propósito de que el valor inclusión no inhiba la misión propia de la universidad: la excelencia del conocimiento. Por otra, un sistema universal de educación superior debe hacer frente al problema del financiamiento del mismo y las razones que lo justifican. En este caso el desafío está en invertir los recursos (sobre todo los públicos) en aquellas instituciones y programas que por su reconocida calidad (certificada en lo posible) entregan una formación seria y rigurosa, aunque inclusiva, en perfecta concordancia con las exigencias sociales y no, necesariamente, con los caprichos del mercado. Las líneas de cohorte que dirimen los límites aceptables de retención y egreso de los alumnos no debiesen establecerse en términos cuantitativos sino cualitativos. El desafío aquí está en garantizar que la inversión social y personal que realiza un alumno se traduzca en el mediano y largo plazo en un real incremento del capital humano y social. La exigencia de una educación superior basada en competencias, que armoniza los perfiles del estudiante y el profesional, desafía a los centros de formación universitaria en cuanto exige de ellos una apertura hacia fuera de la academia (para lograr una real comprensión de las demandas del mercado profesional) y la innovación constante de los currículos y métodos de enseñanza. El desafío es asociar en la justa medida la teoría con la práctica.

Con todo, el nuevo modelo no está libre de riesgos. La universalización de la educación superior con su consecuente aumento de matrículas; el incremento sustantivo del número de universidades y programas; la promoción de nuevos cometidos a la academia vinculados con valores sociales (inclusión, democratización, sanidad pública, etc.) independientes de la generación y promoción del conocimiento, fácilmente pueden conducir a un colapso del sistema. En el caso de la enseñanza del derecho esto puede materializarse en un grado inaceptable de abogados con una precaria instrucción jurídica, cuestión que ha de impactar negativamente a la sociedad. Los esfuerzos encaminados a captar, retener y graduar abogados, sin ninguna consideración a las reales demandas del sistema jurídico, necesariamente ha de afectar la futura empleabilidad de los mismos y por ello a la retribución esperada por el esfuerzo económico y personal invertidos en la obtención del grado. Finalmente, la sujeción acrítica de los currículos y métodos de enseñanza del derecho a las condiciones y exigencias de una economía de libre mercado (que considera a la educación como un bien de consumo entre otros) puede conducir fácilmente a la "captura de las escuelas de derecho" por parte del mercado y a la tecnifica- 
ción de la profesión y la pérdida de la vocación universitaria y humanista del abogado.

Por desgracia, una mirada actual al escenario nacional de la educación universitaria y la enseńanza del derecho pone de manifiesto que, en muchos aspectos, los riesgos se han traducido en dańos efectivos. Con más de tres mil abogados titulados por año; más de un centenar de programas de derecho, la mayoría de dudosa calidad, sin acreditación ni control; con una eliminación progresiva (o reducción inaceptable) de los cursos de formación inicial de carácter humanista (derecho romano, historia del derecho, filosofía, etc.), y con una doctrina que sigue discutiendo sobre las bondades o defectos del método expositivo de la clase magistral o las utilidades de la dinámica del análisis de casos, es posible conjeturar (solo conjeturar) que de no mediar, por un lado, una propuesta seria y comprehensiva (por parte de los teóricos del derecho) sobre la forma de capitalizar de una manera racional las oportunidades que el nuevo paradigma ofrece $y, y$ por otro, una intervención decidida de las autoridades públicas en este punto, los abogados, en unos pocos años más, no solo habrán perdido su importancia como referentes en la conducción del estado y la sociedad sino también habrán perdido para siempre el poco prestigio intelectual del que aún (y solo por tradición) gozan.

\section{BIBLIOGRAFÍA}

Aвramovich, Víctor (1999) "La enseñanza del derecho en las Clínicas Legales de Interés Público”. Cuadernos de Análisis Jurídico Universidad Diego Portales, Serie Publicaciones Especiales, No 9.

Agudelo, Martín (2000) "Hacia un Procesamiento Adecuado de la Justicia: una Propuesta de Enseñanza del Derecho Procesal para la Sociedad del Nuevo Milenio". Revista de Derecho Universidad Central, No 1.

Alvear, Julio (2002) "Algunas Anotaciones sobre la Enseñanza de la Ética Jurídica”. Actualidad Jurídica, No 6, pp. 27.

Amunátegui, Carlos (2007) "La enseñanza del Derecho Romano a través de Gayo. Una experiencia docente”. Ius Publicum, No 18.

Aróstica, Iván (2009) "Formando Abogados Analistas". Actualidad Jurídica, No 19, Tomo II.

Austin, Alexander (1997) "How 'Good' is your Institution's Retention Rates". Research in Higher Education, Vol. 38, N 6, pp. 647-658.

Bascuñán Valdés, Aníbal (1954) Pedagogía Juridica. Santiago: Editorial Jurídica de Chile, 216 pp., p. 177.

Bascuñán Valdés, Aníbal (1961) Manual de Técnica de la Investigación Jurídica. Santiago: Editorial Jurídica de Chile, 217 pp., p. 36. 
Bascuñan Valdés, Antonio (1975) "Postgrado en Derecho. Programa de Magíster". Boletín del Instituto de Docencia e Investigación Jurídicas, No 28-29, pp. 41-50.

Calvinho, Gustavo (2009) "La enseñanza del derecho procesal en el siglo XXI". Revista de Derecho Universidad Católica de la Santísima Concepción, 2, № 20.

Campusano, Raúl (2002) "La Enseñanza del Derecho Informático en Chile. Apuntes para una Respuesta". Actualidad Juridica, No 5.

CaÑas, Rafael; et al. (1974) "Programa del Curso sobre Investigación Jurídica de la Escuela de Derecho de la Universidad Católica de Chile". Boletín del Instituto de Docencia e Investigación Jurídicas, No 22, pp. 175-184.

Carvallo, Sergio (1986) "La Cátedra de Derecho Económico". Temas de Derecho, No 1.

Caprile, Bruno (2000) "La Enseñanza del Derecho: ¿Clase Magistral o Método activo?". Actualidad Jurídica, No 2.

CÁrcamo, Juan (2000) "La Orientación Humanista en el estudiante de Derecho". Revista de Derecho Universidad Central, No 1.

CÁrcamo, Juan (2002) "Cooperación a la Justicia como Aspecto Formativo Fundamental del Estudiante de Derecho". Revista de Derecho Universidad Central, No 3.

CATTÁn, Ángela (2002) "Algunas notas para una Nueva Metodología para la Enseñanza del Derecho Romano". Actualidad Jurídica, No 5.

Celis-Giraldo, Jorge Enrique (2009) "Las acciones afirmativas en educación superior: el caso de los Estados Unidos". Educación y Educadores, 12(2), pp. 103-117.

Coloma, Rodrigo (2006) "Hacia una enseñanza del Derecho Efectiva". Revista Escuela de Derecho, Ańo 7, No 7, pp. 123-141.

Coloma, Rodrigo (2005) "El ocaso del profesor Binns. Un ensayo acerca de la enseñanza del derecho en Chile". Revista Ius et Praxis, Año 11, No 1, pp. 133-172.

Coloma, Rodrigo y Agüero, Claudio (2012) "Los Abogados y las Palabras. Una propuesta para Fortalecer Competencias Iniciales en los Estudiantes de Derecho". Revista de Derecho Universidad Católica de Norte, Ańo 19, No 1, pp. 39-69.

Cruz-Cocke M. Ricardo (2004) "Evolución de las Universidades Chilenas 1981-2004". Revista Médica Chilena, 132: 1543-1549.

Cuneo M., Andrés (1970) "Reforma de las Escuelas de Derecho: el Contenido de la Enseñanza Jurídica”. Boletín del Instituto de Docencia e Investigación Jurídicas, No 3, pp. 32-42.

Cuneo, Andrés (1971) "Modelo para el Desarrollo de la Metodología Integrada de una Unidad de Materia". Boletín del Instituto de Docencia e Investigación Jurídicas, No 1, pp. 38-70. 
Devoto, Carolina (2012) "El Método de Resolución de Casos en la Enseñanza del Derecho". Actualidad Jurídica, No 25.

Devoto, Carolina (2014) "Hacia una Caracterización teórica del Docente Universitario en la Carrera de Derecho". Actualidad Jurídica, No 30.

Donoso, Andrés (2001) "La Educación Jurídica: ¿Un Problema Insoluble?”. Revista de Derecho Universidad Finis Terrae, Año V, No 5.

Elgueta, Francisma y Palma, Eric (2014) "Una Propuesta de Clasificación de la Clase Magistral Impartida en la Facultad de Derecho". Revista Chilena de Derecho, Vol. 41, No 3.

EsCANDón, Jesús (2006) "Inquietudes persistentes respecto a la enseñanza de la Filosofía del Derecho". Sociedad Chilena de Filosofía Jurídica Social Anuario de Filosofía Jurídica y Social, No 24.

Espinoza, Oscar (2005) "Privatización y Comercialización de la Educación Superior en Chile: Una Visión Crítica”. Revista de Educación Superior, Vol. XXXIV, 3, No 135, 41-60 pp.

FigueroA, Gonzalo (1974) "Hacia Una Nueva Concepción de los Estudios de Derecho". Boletín del Instituto de Docencia e Investigación Juridicas, No 24, pp. 86-125.

Friedman, Lawrence (1972) "Cultura Legal y Desarrollo Social”. Boletín del Instituto de Docencia e Investigación Jurídicas, No 11, pp. 43-61.

Guerrero, Roberto (1997) "La Enseñanza del Derecho en Chile: una Visión Crítica”. Revista Chilena de Derecho, Vol. 24, No 1.

Gómez Duque, Luis Fernando (1971) "Curriculum y Contenido de la Enseñanza”. Boletín del Instituto de Docencia e Investigación Jurídicas, No 8, pp. 98-113.

Green, John A. (1972) "Distintas Formas de Test". Boletín del Instituto de Docencia e Investigación Jurídicas, No 12, pp. 160-164.

Guzmán B., Alejandro (2006) "La Enseñanza del Derecho. Historia y Perspectivas" en Anales del Instituto de Chile. Santiago: Instituto de Chile, 490 pp.

HanitchaK, John (1972) “Medición y Evaluación”. Boletín del Instituto de Docencia e Investigación Jurídicas, No 12, pp. 150-159.

Hervada, Francisco (1989) "La Enseñanza del Derecho Natural y del Derecho Canónico en las Facultades de Derecho". Revista Chilena de Derecho, Vol. 16, No 3, p. 565.

Hübner Gallo, Jorge (1952) Manual de Introducción a las Ciencias Jurídicas y Sociales. Santiago: Editorial Jurídica de Chile, 483 pp.

Hübner Gallo, Jorge (1954) Manual de Filosofía del Derecho. Santiago: Editorial Jurídica de Chile, 277 pp.

Jiménez, Manuel (2011) "La movilidad académica como factor auxiliar del aprendizaje del Derecho". Revista de Derecho, Universidad Católica de la Santísima Concepción, No 24, Vol. 2. 
Lagreze, Feliz (1972) "Ideas para un Programa de Derecho y Desarrollo". Boletín del Instituto de Docencia e Investigación Jurídicas, No 12, pp. 95-101.

Manning, Bayless (1989) "Atributos del Abogado". Temas de Derecho, No 1.

Lazo, Patricio (2011) "Formación Jurídica, Competencias y Métodos de Enseñanza: Premisas". Revista Ius et Praxis, Año 17, No 1, pp. 249262.

Shakhtur, Ali (2007/2008) "El Rol del Abogado: ¿Negociador?”. Temas de Derecho, No 1 y 2.

Montes, Hugo (1972) "Pedagogía y Derecho" (versión de cinta magnetofónica). Boletín del Instituto de Docencia e Investigación Jurídicas, № 11, pp. 11-25.

Moya, Moisés (1972) "Rol de la Evaluación en Educación". Boletín del Instituto de Docencia e Investigación Jurídicas, No 12, pp. 139-141.

Ortiz Quiroga, Luis (1970) "Introducción al Boletín del Instituto de Docencia e Investigación Jurídicas". Boletín del Instituto de Docencia e Investigación Jurídicas, No 1, p. 3.

OtÁrola, Waldo (2000) "La Enseñanza del Derecho". Revista de Derecho Universidad de Concepción, No 207.

Pacheco Gómez, Máximo (1958) Introducción al Estudio de las Ciencias Jurídicas. Santiago: Editorial Universitaria, 709 pp.

Palomino, José F. (1998) "David Sobrevilla y la enseñanza de la Filosofía del Derecho en la Universidad de Lima". Anuario de Filosofía Jurídica y Social. No 16.

Pedrals, Antonio (1984) "La Enseñanza, de la Teoría General del Derecho". Anuario de Filosofía Jurídica y Social, Sociedad Chilena de Filosofía Jurídica Social, No 2.

Peláez, Manuel (2004) "Las Asignaturas Jurídicas en las Licenciaturas de Especialidad en Italia en el Marco de la Reforma Europea de la Educación Universitaria”. Revista de Derecho Pontificia Universidad Católica de Valparaíso, XXV, pp. 331-338.

Peña, Carlos; et al. (1994) Evolución de la Cultura Jurídica Chilena. Santiago de Chile: Corporación de Promoción Universitaria.

Pezzeta, Silvina (2008) "La enseñanza del Derecho desde una perspectiva sociológico jurídica. Un estudio de caso en una Facultad de Derecho". Revista de Derecho Universidad Católica del Norte, Vol. 15. No 2.

Retamal Ávila, Julio (1973) "Bibliografía Chilena sobre Metodología de la Enseñanza del Derecho". Boletín del Instituto de Docencia e Investigación Jurídicas, № 20, pp. 148-170.

Salas, Julio (1991) "La Enseñanza del Proceso". Revista de Derecho Universidad de Concepción, No 189. 
Seidman, Robert B. (1972) "Derecho y Desarrollo: Un Modelo General". Boletín del Instituto de Docencia e Investigación Jurídicas, No 12, pp. 51-76.

SQuella, Agustín (1995) “QQué he Aprendido Enseñando Filosofía del Derecho?”. Gaceta Jurídica, No 178.

TAelI, Raquel; et al. (2014) "Los aportes de paradigmas complejos y constructivistas para la enseñanza de la ciencia jurídica”. Ius et Praxis, No 1 .

TAPIA VAldÉs, Jorge (1971) "La Escuela de Derecho y el Cambio Social". Boletín del Instituto de Docencia e Investigación Jurídicas, No 7, pp. 94-106, p. 95.

Thome, Joseph R. (1972) "El Derecho Como Instrumento de Cambio Social: Comentarios Sobre un Modelo de Derecho y Desarrollo". Boletín del Instituto de Docencia e Investigación Jurídicas, No 12, pp. 77-94.

Trow, Martin (1973) Problem in the Transition from Elite to Mass Higher Education. Berkeley: Carnegie Comision on Higher Education, 57 pp.

Tunc, André (1970) "Salir del Neolítico". Boletín del Instituto de Docencia e Investigación Jurídicas, No 1, pp. 6-22.

Valenzuela, Rafael (1971) "Metodología del Aprendizaje del Derecho". Boletín del Instituto de Docencia e Investigación Jurídicas, No 1, pp. 23-37;

Valenzuela, Rodrigo (2002) "El derecho y las humanidades". Revista de Derecho Universidad Austral de Chile, Vol. XIII.

Veloso, Adolfo (1998) "Acerca del Derecho Internacional y su Enseñanza”. Revista de Derecho Universidad de Concepción, No 207. 